\title{
The role of index trading in price formation in the grains and oilseeds markets
}

Article

Accepted Version

Gilbert, C. L. and Pfuderer, S. (2014) The role of index trading in price formation in the grains and oilseeds markets. Journal of Agricultural Economics, 65 (2). pp. 303-322. ISSN 14779552 doi: https://doi.org/10.1111/1477-9552.12068 Available at https://centaur.reading.ac.uk/41013/

It is advisable to refer to the publisher's version if you intend to cite from the work. See Guidance on citing.

Published version at: http://dx.doi.org/10.1111/1477-9552.12068

To link to this article DOI: http://dx.doi.org/10.1111/1477-9552.12068

Publisher: Wiley

All outputs in CentAUR are protected by Intellectual Property Rights law, including copyright law. Copyright and IPR is retained by the creators or other copyright holders. Terms and conditions for use of this material are defined in the End User Agreement.

\section{www.reading.ac.uk/centaur}

\section{CentAUR}

Central Archive at the University of Reading

Reading's research outputs online 


\title{
The role of index trading in price formation in the grains and oilseeds markets
}

\author{
Christopher L. Gilbert and Simone Pfuderer ${ }^{1}$ \\ [Original submitted October 2013, Revision received February 2014, Accepted February \\ 2014]
}

\begin{abstract}
We use both Granger-causality and instrumental variables (IV) methods to examine the impact of index fund positions on price returns for the main U.S. grains and oilseed futures markets. Our analysis supports earlier conclusions that Granger-causal impacts are generally not discernible. However, market microstructure theory suggests trading impacts should be instantaneous. IV-based tests for contemporaneous causality provide stronger evidence of price impact. We find even stronger evidence that changes in index positions can help predict future changes in aggregate commodity price indices. This result suggests that changes in index investment are in part driven by information which predicts commodity price changes over the coming months.
\end{abstract}

Keywords: Grainger causality, instrumental variables, futures markets, grains and oilseeds, hedging, options

JEL Classifications: C26, C58, D84, G13, Q02

Christopher Gilbert is with the Department of Economics and Simone Pfuderer is with the School of Social Sciences, both at University of Trento, via Inama 5, 38122 Trento, Italy. Simone Pfuderer is the contact author: simone.pfuderer@unitn.it. The initial draft of this paper, under a slightly different title, was prepared for the workshop "Understanding Oil and Commodity Prices" organized by the Bank of England, the Centre for Applied Macroeconomic Analysis, Australian National University, and the Money, Macro and Finance Study Group (MMFSG), London, 25 May 2012. Material from the paper was presented at the CEPS workshop "Price formation in commodities markets: the world after financialization", Brussels, 30 September 2013. We are grateful to participants at the MMFSG workshop and to Ann Berg for comments on the CEPS presentation; and to referees for helpful comments. The authors take sole responsibility for all opinions stated. 


\section{Introduction}

There has been extensive academic and policy discussion of the possible role of financialization, and in particular the role of index investors, in generating high commodity prices. A particular focus has been the grains price movements in 2007-08 and again in 201011 because of their importance as staple foods. Mayer (2011) and UNCTAD (2011, chapter 5) provide summaries of these debates.

Index investors hold portfolios of commodity futures contracts with the aim of replicating returns on one of a small number of tradable commodity futures indices, of which the S\&P GSCI and the Dow Jones-UBS indices are the most important. Index investors may either hold positions directly, as is the case with some large pension funds, or indirectly through fixed-floating swaps provided by "index providers" (typically investment banks). In the latter case, the index provider will offset the resulting short exposure by purchase of futures contracts, although not necessarily on an automatic (non-discretionary) basis (see Sanders and Irwin (2011b) for a more detailed discussion).

Index investment in commodity futures may be motivated by either or both of two considerations. The first is what we term a passive strategy of portfolio diversification (Markowitz, 1952; Stoll and Whaley 2010). Gorton and Rouwenhorst (2006) argued that, over the period July 1957 to December 2004, returns on the S\&P GSCI compared favourably with those on equities although with slightly greater risk, and dominated bonds in terms of the Sharpe ratio. Over the period they considered, commodity returns had a statistically insignificant correlation with equities and a low but statistically significant negative correlation with bond returns. These relationships suggest that investment in a long passive commodity fund could have bought diversification of an equities portfolio at a lower cost than through bonds. According to this view, index investment is uninformed and should not influence returns.

The second possible motivation is that of taking a position on the basis of expectations of the likely risk and returns on the "commodity asset class" (or components of this class) relative to returns on other asset classes (equities, fixed interest, real estate etc.) see Scherer and He (2008). We refer to this as an active investment strategy. In this case, index investment is based on information or expectations relating to future market positions and has the potential to influence commodity returns. 
The S\&P GSCI is probably the most widely tracked tradable commodity futures index. This index gives a very high weight to energy commodities, in particular crude oil and natural gas. Agricultural commodities have only a small weight - of the order of $10 \%$ of the total for grains and vegetable oils. ${ }^{2}$ The Dow Jones-UBS index caps the energy weight at one third leaving more space for agricultural futures - of the order of $20 \%$ for grains and vegetable oils (see Gilbert, 2010a). As a consequence, only a small proportion of money invested in commodity index investment finds its way to agricultural markets.

Despite this, Commodity Futures Trading Commission (CFTC) figures show that index investment accounts for a large proportion of long-side open interest in U.S. grains and oilseeds futures markets between 2006 and 2011 as shown in Figure 1. The shares are lowest for Kansas City Board of Trade (KCBT) wheat at $15.3 \%$ on 3 January 2006 at the start of our 2006-11 sample and 26.2\% on 27 December 2011 at the end of our sample. The shares are highest for Chicago Board of Trade (CBOT) wheat at 50.5\% on 3 January 2006 and $47.0 \%$ on 27 December 2011.

The CFTC also reports the number of commodity index traders (CITs). This number, typically between 20 and 30, is fairly consistent over time and over commodities, in line with the fact that many CITs are tracking the same indices. Individual CITs will therefore only account for a small proportion of total trades on any market. The CIT category includes traditional index investors tracking the main indices but also those that follow sector specific indices (Irwin and Sanders 2012a; Sanders and Irwin 2013).

A number of politicians and market practitioners have made the claim that CIT trades impact commodity prices - see, for example, the comments of hedge fund manager Michael Masters (Masters 2008). However, the academic literature predominantly fails to find such price effects. We argue that these results exaggerate the lack of impact of index trading on food commodity prices because Granger-causality tests, the main approach used in the academic literature, lack statistical power. We suggest a contemporaneous test based on instrumental variable estimation to exploit the contemporaneous correlation between changes in CIT positions and futures price returns. In addition, we extend the analysis to consider the relationship of changes in CIT positions and changes in the IMF's aggregate commodity price indices as measures of changes in overall commodity prices, including energy and

\footnotetext{
${ }^{2}$ Changes in prices and periodic rebalancing result in changes in index weights over time.
} 
metals prices. Our results suggest that index investment is in part driven by information that predicts changes in commodity prices in future months.

The paper proceeds as follows. A brief literature review is followed by a section describing the data and variables included in the analysis and one on contemporaneous correlations. Granger-causality and instrumental variables (IV) methodologies are introduced before results of the two tests are presented for the grains and soybean complex contracts. The final set of tests that we analyze relates changes in an index of overall CIT positions in US agricultural futures markets to changes in the IMF's commodity price indices. The paper concludes with a discussion of the evidence on the impact of commodity trader positions on returns.

\section{Literature review}

We review here the existing literature on the impacts of index investment in agricultural futures markets in the wider context of the finance literature on the price impacts of trading. A considerable body of research in that literature demonstrates that large trades impact prices in a range of financial markets see, for example, Scholes (1972), Shleifer (1986) and Holthausen et al (1987). There are two principal mechanisms through which changes in the positions held by a large trader or group of traders might impact futures prices. First, if the traders in question have private information about the price fundamentals, their trading will communicate this information to the market resulting in the information becoming impounded in the price. In the agricultural context, such private information might result from an ability to forecast future production, consumption or end-year stocks. Alternatively, it may result from a better (or, at least, different) understanding of trends in global macroeconomics or of the political economy processes of regulation or intervention.

According to market microstructure theory, this information impounding process gives rise to permanent prices changes, i.e. there should be no tendency for the futures price in question to revert over time, e.g. O’Hara (1995), Stoll (2000) and de Jong and Rindi (2009). These considerations might imply an impact from an active commodity investment strategy on grains and oilseeds prices if the information in question would not otherwise have been available to these markets.

The second mechanism results from lack of market liquidity. An illiquid futures market is one in which the short-run elasticity of supply of counterparty orders is relatively low. Large buy orders will push the price up through the order book and conversely with 
large sell orders. In Amihud and Mendelson's (1986) model, asset returns contain an illiquidity premium reflecting the infrequency of trading. The liquidity impacts of trades known to be uninformed are transient as fresh counterparty orders come to the market. Liquidity considerations might imply a price impact in relatively less liquid grains and oilseeds markets but in this case prices would be expected to revert over time.

In practice, uninformed traders do not know whether any given price movement is the result of informed or uninformed trades. They therefore attach a probability to trades being informed based on the noise-to-signal ratio in the market - see Kyle (1985). Informed purchases will result in a rise in the market price but of a smaller order than the amount by which the informed traders estimate the fundamental to have risen. Partial impounding maintains the profitability of market research thereby finessing the Grossman and Stiglitz (1980) paradox. $^{3}$

It is also possible that there is no direct impact of CIT trading on futures prices but that movements in these prices are driven by the same factors that result in changes in CIT positions. If this is the case, standard statistical tests may suggest a link from CIT trading to futures price formation despite the absence of a causal link between them.

These questions have recently been examined in the futures market context by a number of papers. Extensive reviews of the wider literature on the impact of speculators on futures prices are provided by Irwin and Sanders (2011, 2012b) and Irwin (2013) for agricultural markets and Fattouh et al (2013) for the crude oil market. The question of the impact of futures prices on spot prices has also been given renewed attention, for example by Hernandez and Torero (2010), Acharya et al (2011) and Sockin and Xiong (2013) confirming that future prices impact spot prices.

Granger-causality analysis has become established as the standard econometric methodology used to investigate the impact of position changes on futures market prices. We consider some recent studies that have tested for Granger-causality from CIT positions to futures prices. Brunetti and Büyüksahin (2009) use daily data on positions that are not publicly available to test for Granger-causality from daily position of commodity index traders in the corn market to daily corn futures. They do not find any evidence of Grangercausality in the corn market. Most other studies use the CFTC weekly data on positions

\footnotetext{
${ }^{3}$ Grossman and Stiglitz (1980) noted that in informationally efficient markets agents have no incentives to gather the information required for that efficiency since prices would adjust as soon as they attempt to trade on this information.
} 
which are publicly available from January 2006. Stoll and Whaley (2010) include all twelve agricultural markets for which index position data are published on a weekly basis by the CFTC. Their study covers the period from 2006 to 2009. They do not find any evidence of Granger-causality except in the case of cotton. Over the period 2006 to 2010, Rouwenhorst and Tang (2012) find that changes in index investor positions do not Granger-cause returns in eleven of the twelve agricultural commodities studied. For the single commodity for which Granger-causality is found, the relevant coefficient is estimated as negative. Sanders and Irwin (2011a) analyze U.S. grain prices. They use CFTC data to examine whether index funds impacted U.S. grains futures prices over the period 2004-09, thus including 2004 and 2005 for which position data of index traders are not publicly available. They fail to establish any Granger-causal link from changes in the futures positions attributed by the CFTC to index providers to the returns on nearby grains futures prices. Mayer (2012) analyzes the wheat, maize, soybeans and soybean oil markets as well as four non-agricultural markets. $\mathrm{He}$ includes index positions and money manager positions in the model to test for Grangercausality. Between June 2006 and June 2009, Granger-causality from index positions to prices is established in four of the eight markets (soybeans, soybean oil, copper and crude oil). For money managers, Granger-causality from positions to prices is only established in the maize market.

Sanders and Irwin (2011b) use a Seemingly Unrelated Regression (SUR) system framework to test for Granger-causality from swap dealer positions (a good proxy for commodity index trader positions in agricultural markets, Sanders et al, 2010), to futures prices in the period from 2006 to 2009. They do not find any evidence of Granger-causality. Capelle-Blancard and Coulibaly (2011) apply a similar method but using the CIT position data over the period 2006 to 2010 . They only find evidence of causality from index positions to prices in the live cattle market before September 2008 and cocoa for the period between September 2008 and December 2010. Aulerich et al (2012) also use the SUR framework but with data over the period from January 2004 to September 2009 from the Large Traders Reporting System database. Out of the twelve markets they study, Granger-non-causality from index positions to prices is rejected in three markets (feeder cattle, lean hogs, Kansas City Board of Trade wheat). Hamilton and Wu (2013) test if notional exposure in the previous period predicts prices. They do not find any evidence in the markets they study. Overall, the results in the literature based on Granger-causality analysis are predominantly negative. 
Tang and Xiong (2012) take a different approach. They analyze return correlations of non-energy commodities with oil. They find that the correlation of oil returns with those of commodities that are not included in the two most important commodity indices increased significantly less than those of the commodities in the indices. Their results suggest that index investment impacted prices.

However, we argue that the results based on Granger-causality analysis exaggerate the lack of impact of index trading on food commodity prices. At the same time, positive findings in relation to Granger-causality do not necessarily or always imply structural causality.

\section{Data}

\section{Position data and variables}

Weekly data on positions are available from the CFTC in Commitment of Traders (COT) report. The reports are published each Friday and show open interest on the previous Tuesday. The COT reports include information on open interest for two categories of traders - commercial and non-commercial traders. The aim of the categorization was to group traders according to their general purpose for trading in futures markets (CFTC, 2006).

With the increase in long-only index investment, the information provided in the main report was judged to have lost some of its relevance as traders in the same category could not be considered to have a similar general purpose for trading. As a consequence, on January 5 , 2007 the CFTC started to publish a Supplemental report (Supplementals) that shows positions for three categories of traders - commercials, non-commercials and index traders. The report includes positions for the five largest US grains and oilseeds markets (CBOT maize, soybeans, soybean oil, wheat and KCBT wheat). Comparable data for 2006 was published with the first report in January 2007. Our sample therefore starts on 3 January 2006. The final date in our sample is the 27 December 2011.

The index trader category in the Supplementals contains traders that are included in the commercial category of the COT report (e.g. swap dealers) and in the non-commercial categories of the main COT report (e.g. managed funds, pension funds and other institutional investors). The Supplementals are the best publicly available data source for index investor positions but have important limitations. Data are only available on a weekly basis and index 
positions and prices can experience significant changes within a week, or even within a day. However, no data at a higher frequency are publicly available. ${ }^{4}$

In addition, the Supplementals classify traders as "index traders" if index related trading is the main trading strategy of that trader. The report includes all positions held by those traders in the index trader category not just those that are index related. Furthermore, the positions on the futures market are the residual after internal netting of positions by the traders. As a consequence, the measure published in the Supplementals might under- or overreport actual index trading. It might over-report positions as not all positions by the traders classified as "index traders" are index-related. It might under-report index trading as the position on the futures market is the residual after internal netting of positions by the traders (CFTC, 2006).

Our measure of index investment positions is constructed based on the CFCT data. The absolute measure is net long positions held by commodity index traders in the individual markets. It is calculated as long positions minus short positions by index traders and scaled by $1 / 1,000,000$.

\section{Price data and variables}

Commodity futures prices are available from the futures exchanges and from other data providers. ${ }^{5}$ We use returns on the nearby future as the price measure. Our price variables are Tuesday-to-Tuesday logarithmic returns to match the position data. If a Tuesday is not a trading day, the closing price on the trading day preceding Tuesday is used.

A number of different conventions are used in the futures literature for rolling contracts (i.e. for moving from the expiring contract to the next nearby). The five grains and oilseeds contracts considered in this paper all expire on the 14th of the expiry month or the immediately prior trading day if the 14th falls at a weekend or on a holiday. We roll contracts on the first trading day of the month in which a contract expires. Returns over the roll date are defined to be contract-consistent, i.e. they exclude roll returns.

\footnotetext{
${ }^{4}$ Ann Berg has suggested that we should use the monthly data from the CFTC's Index Investment reports in place of the weekly data from the Supplemental COT reports. The Index Investment data are more comprehensive (they cover non-agricultural as well as agricultural futures markets) and generally considered to be more accurate. However, use of these data would dictate use a shorter sample and require the complete set of tests to be performed on monthly rather than weekly data. Publication commenced in on a quarterly basis in December 2007 but only became monthly in June 2010, towards the end of our sample.

${ }^{5}$ The price data used here were sourced from Norma's Historical Data which is no longer active.
} 


\section{Methodology}

The analysis falls into three parts. First, we look at the contemporaneous correlations between position changes and price returns. Second, we apply the standard Granger causality testing procedure which relies on the impact of lagged position changes on returns. Finally, we revert to contemporaneous impacts using an instrumental variables approach.

\section{Contemporaneous Tests}

CIT position changes are significantly correlated with futures returns in the same week. These correlations are broadly consistent across commodities. Correlations and their associated $\mathrm{t}$ statistics are given in Table 1 . The correlations are positive and are all statistically significant. These results are in line with previous findings (see, for example, discussions in Bryant et al, 2006, Stoll and Whaley, 2010; Sanders et al, 2009).

It is clear from Table 1 that there is an association between CIT positions and futures returns. However, this does not constitute evidence for or against causality from index traders to prices (Newbold, 1982) since causation could run either way or there could be an unseen joint cause of both returns and CIT position changes. However, if these positive associations arise from a causal link from returns to position changes, this would require that CIT traders are trend followers. If instead, CIT traders are seeking to buy low and sell high, the causal link from returns to position changes should be negative and would offset the positive link from position changes to returns.

\section{The Granger-Causality Methodology}

The Granger-causality methodology is the standard approach employed in this literature to investigate the possible causal impact of position changes. It successfully circumvents the problems associated with the direction of causality which arise in relation to correlation analysis but the tests may exhibit low power if causal impacts happen with only a short lag. As is the case with all regression-based methods, Granger-causality tests vulnerable to the "omitted variable" criticism.

Let $\mathrm{r}$ be the return of interest and $\mathrm{x}$ be the candidate position change. The Granger-causality test asks whether knowledge of the position change history $x_{t-1}, x_{t-2}, \cdots$ given knowledge of the return history $r_{t-1}, r_{t-2}, \cdots$ improves the accuracy of forecasts of the current return rt. If 
forecast accuracy is improved this can only be because the position changes $\mathrm{x}$ are causally related to the returns $r$. The test employs an $\operatorname{ADL}(p, q)$ model

$$
r_{t}=\kappa+\sum_{j=1}^{p} \alpha_{j} r_{t-j}+\sum_{j=1}^{q} \beta_{j} x_{t-j}+u_{t}
$$

In general, investigators set $q=p$ so that the two lag distributions are symmetric. In that case, equation (1) may be considered as the first equation of a bivariate $\operatorname{VAR}(p)$. The model does not allow any contemporaneous impact (the $x$ lag distribution commences at 1). The Granger-causality test statistic is the Wald $F$ test of the hypothesis $H_{0}: \beta_{1}=\ldots=\beta_{p}=0$. If this hypothesis is rejected, we say that the position changes $x$ Granger-cause the returns $r$.

Granger-causality does imply a causal link between the causal variable $x$ and the effect variable $r$ but it does not imply that $x$ is a structural cause of $r$ most obviously because some third variable $z$ may be a joint cause of both $x$ and $r$. If data are available on $z$, equation (1) may be expanded as

$$
r_{t}=\kappa+\sum_{j=1}^{p} \alpha_{j} r_{t-j}+\sum_{j=1}^{p} \beta_{j} x_{t-j} \sum_{j=1}^{p} \gamma_{j} z_{t-j}+u_{t}
$$

The Granger-causality test statistic is the Wald $F$ test of the hypothesis. $H_{0}: \beta_{1}=\ldots=\beta_{p}=0$. Since returns are influenced by multiple factors, many of which are unmeasured and even unmeasurable, the claim that the causal relationship between $x$ and $r$ in equation (1) reflects some third variable $z$ is vacuous unless this third variable is specified. It is a strength of the Granger-causality methodology that it permits the analyst to make qualified statements about causal relationships without fully specifying the channels through which these relationships occur.

The results of a Granger-causality test may depend on the lag length $p$ selected in equation (1). The recommended procedure is to start with a generously high value for $p$ and then to test down using, for example, the Akaike Information Criterion (AIC). Often one arrives at the situation of $p=1$ so that equation (1) reduces to

$$
r_{t}=\kappa+\alpha_{1} r_{t-1}+\beta_{1} x_{t-1}+u_{t}
$$

In this case, the Granger-causality test is equivalent to the Student $t$ statistic on the coefficient $\beta_{1}$. 
Granger-causality tests answer the question whether there is a causal relationship between the candidate causal variable and the effect variable. However, there is an important qualification. While a finding that $x$ Granger-causes $r$ does imply a causal link between $x$ and $r$, the link may not be structural and may not be direct. Granger-causation therefore differs from structural causation (Hoover, 2001). If this qualification applied in the current context, there can be no implication that limitation or prohibition of index investment would have affected the high food price rises experienced over recent years.

This qualification also implies that the Granger-causality test equation (1) cannot in general sustain a structural interpretation and hence the $\alpha$ and $\beta$ coefficients are not directly interpretable. Either prediction is improved or it is not. This is well understood in the case in which $p>1$ but confusion can set in when equation (1) reduces to equation (3) with $p=1$ in which case authors often insist on a one-sided test. We report two-sided tail probabilities throughout in the case in which $p=1$ to maintain consistency with those cases in which $p>$ 1.

\section{Contemporaneous Tests}

Market microstructure models involving informed, uninformed and liquidity (noise) traders imply that trades by informed traders result in all or part of their private information becoming instantaneously impounded in prices at the time of their trades (O'Hara, 1995, chapter 3). Consequently, prices follow martingale processes and price changes are unpredictable. According to these theories, any impact of index-based or other trading on agricultural futures markets should take place over a very short period of time. In the present study, in which we are restricted to the use of weekly data, such impacts will appear as contemporaneous. This may account for the positive correlations between changes in CIT positions and futures returns documented above. Furthermore, according to this view, the data should fail to support Granger-causality despite the apparently contemporaneous causal link from CIT trades to futures returns since the Granger-causality tests are based on past trades, the impact of which will already have been impounded in prices.

This is a stronger result than that implied simply by the Efficient Markets Hypothesis $(\mathrm{EMH})$. The Commitment of Traders (COT) reports relating to each Tuesday are released on the following Friday. The EMH does not preclude the possibility that a trade in week $t$ can influence price changes on the first three days (Wednesday to Friday) of week $t+1$ prior to publication of the COT reports. Market microstructure theory does rule out this possibility 
since the price impact of any trade takes place when that trade is made, not when the fact that it has been made is published. Let $f_{\mathrm{t}}$ be the futures price at date $t, \Omega_{\mathrm{t}}$ be the complete public information set in period $t$ and $x_{\mathrm{t}}$ be the vector of trades made in period $t$ but only published at $t+\delta$ where $0<\delta<1$, so that $\Omega_{r+\delta}=\Omega_{t} \cup\left\{x_{t}\right\}$. The EMH implies $E\left[f_{t+1} \mid \Omega_{t}\right]=f_{t}$ while market microstructure theory implies the stronger condition $E\left[f_{t+1} \mid \Omega_{t+\delta}\right]=f_{t}$.

This argument implies that one should be sceptical about the possibility of Grangercausality tests uncovering causal relationships between position changes and futures returns. In practice, the instantaneous impounding of information implied by the theory will take place over a short period of time, suggesting that Granger-causality tests may have greater power in higher rather than lower frequency data. It is therefore, perhaps, unremarkable that the literature summarized above fails to find Granger-causality in using the CFTC weekly data. Reaction times may also be slower in less liquid markets where Granger-causality tests may be more powerful.

These considerations suggest that the widespread failure for Granger-causality tests to demonstrate causal impact from CIT trading may simply be indicative of the low power of the Granger-causality methodology in this context. An alternative approach is to return to the contemporaneous correlations documented above and to relate the current futures return $r_{\mathrm{t}}$ to the contemporaneous position change $x_{\mathrm{t}}$

$$
r_{t}=\kappa+\alpha_{1} r_{t-1}+\beta_{0} x_{t}+u_{t}
$$

For comparability with equation (3), we continue to include the lagged return $r_{\mathrm{t}-1}$ even though the theory suggests its coefficient should be zero. Effectively, we are therefore considering the partial correlations between futures returns and changes in index positions. Partial correlations are subject to the same problems of interpretability as the crude correlations considered earlier. Interpretability is obtained by projecting the position changes into a space spanned entirely by lagged variables. This is equivalent to the estimation of equation (4) using Instrumental Variables (IV), where the instruments use a vector of $z_{\mathrm{t}-1}$ variables drawn from the lagged information set $\Omega_{\mathrm{t}-1}$. Market microstructure theory predicts a positive sign. This would suggest testing the null hypothesis of no causal relationship $H_{0}: \beta_{0}=0$ against the one-sided alternative $H_{1}: \beta_{0}>0$ and thus employing tail probabilities based on one-sided tests. However, to be consistent with the Granger-causality tests, we also report two-sided tail 
probabilities for the contemporaneous tests, which will therefore be conservative estimates of the probabilities under the null hypothesis of no impact.

This test is, in the first instance, a structural causality and not a Granger-causality test. Its validity relies on three considerations. Firstly, it relies on the market microstructure theory which entails that price determination on financial markets reflects the entire information set available at the date in question. Secondly, it relies on the validity of the instrument set. Let the set of additional instruments be $z_{\mathrm{t}-1}$ so that the complete set of instruments is $w_{t}{ }^{\prime}=\left(\begin{array}{lll}1 & r_{t-1} & z_{t-1}\end{array}\right)$. The validity of the test defined by equation (4) depends on there being no direct impact for the $z_{\mathrm{t}-1}$ variables on the return $r_{\mathrm{t}}$. This claim can be tested by the Sargan (1958) instrument validity test. Thirdly, it requires any other contemporaneous variable omitted from equation (4) to be uncorrelated with the position change variable $x_{\mathrm{t}}$. This clearly cannot be guaranteed unless the omitted variable is specified, in which case it can be added to the equation as an additional regressor. In this respect, the contemporaneous test based on equation (4) is no different from the Granger causality test based on equation (3). If a causal impact is found, it is therefore necessary to acknowledge that this may be indirect and through a possibly unspecified third variable. However, valid instrumentation does allow us to rule out the possibility that the causation is from the futures return to the position change.

The fact that the instrument set is drawn entirely from the lagged information set $\Omega_{\mathrm{t}-1}$ allows us to draw a further parallel with Granger-causality tests. Instrumental variables (IV) estimation is formally equivalent to Two Stage Least Squares implying that we may regard the test defined by equation (4) as equivalent to a Granger-causality test on the variable $\hat{x}_{t}=\hat{\pi}^{\prime} w_{t-1}$ where $\hat{\pi}$ is the least squares coefficient vector from the reduced form regression $x_{t}=\pi^{\prime} w_{t-1}+v_{t}$

\section{Results}

\section{Granger-causality tests}

We use ordinary least squares to perform the tests and report test statistics based on robust standard errors. The results for grains and soybeans are shown in Table 2. ${ }^{6}$ Using the AIC, the model with one lag is selected for all four commodities. We fail to find Granger causality in any of the four cases at the 5\% level. At the $10 \%$ level, index investment Granger-causes

\footnotetext{
${ }^{6} \mathrm{We}$ report the estimated coefficients, $\mathrm{t}$ statistics and associated $\mathrm{p}$-values for the lagged CIT position variable. For brevity, we omit the estimated intercept and lagged return coefficients.
} 
corn but with a negative coefficient. These results therefore broadly confirm those reported elsewhere in the literature.

The soybean oil contract is closely linked to the less actively traded soybean oil and soybean meal contracts through the "crush spread" which allows processors to hedge the soybean processing margin. CFTC figures show that CIT positions in the soybean market are up to twice as large as those in the smaller soybean oil market. Positions in the soybean meal market were insufficiently large for the CFTC to cover them in the Supplemental COT reports (although these were added in 2013). For these reasons, it is natural to consider the soybean oil and meal markets in conjunction with the larger and more liquid soybean market.

Table 3 shows the results of Granger-causality tests for the soybean oil and meal contracts. The candidate causal variables are the changes in soybean oil and soybean CIT positions. Three lags are required in the case of the test for the soybeans oil contract. The results show that changes in index positions in both markets Granger-cause soybean oil price returns. The results do not throw up any sign issues. Although there is always the possibility that the apparent causal relationship is explained by an unspecified third variable, it seems reasonable to conclude that index positions in the soybean market have impacted soybean oil prices. The tests for the soybean meal contract fail to establish Granger-causality.

\section{Contemporaneous tests}

We now turn to the contemporaneous estimates based on equation (4). The estimating equations use a common set of instruments across all four contracts, all of which are dated $t$ 1. These instruments fall into two groups. First, because investors see the grains and soybeans contracts as a group of related contracts, we use the complete set of four lagged returns $r_{\mathrm{t}-1}$ and the four lagged position change variables $x_{\mathrm{t}-1}$ as instruments. Second, index investors are likely to be motivated by recent returns on the major indices and by perceptions of market riskiness. We therefore use the lagged change of the Dow Jones-UBS commodity price index to capture past returns and the level of the VIX volatility index on the previous Tuesday as an estimate of riskiness. The Dow Jones-UBS index is more relevant to investors in agricultural futures than the alternative S\&P GSCI which has a low agricultural weight. VIX is a measure of the implied volatility of the S\&P500 index of US equities prices and is widely regarded as a measure of the perceived riskiness of the entire range of financial markets. 
The test results are reported in Table 4 for the grains and soybeans markets. They reject the hypothesis of no impact from changes in CIT positions for both soybeans and KCBT wheat. The Sargan test fails to reject instrument validity in all four cases.

The p-values associated with the Student tests for both soybeans and KCBT wheat are both less than $3 \frac{1}{2} \%$. Taking the four tests as independent, if there were no impact from CIT positions in any of the four markets considered, the binomial probability of obtaining two or more rejections at the $3 \frac{1}{2}$ per cent level would be less than one per cent. We conclude that there is strong evidence from the contemporaneous tests of a causal relationship between changes in index positions and grains and oilseeds returns.

Table 5 reports estimates of the contemporaneous tests using equation (4) for soybean oil and soybean meal. The instruments are those used for the estimates reported in Table 4 plus, in the case of soybean oil, lagged soybean oil returns and CIT positions. The instrument validity tests are satisfied. There is strong evidence of contemporaneous causality on the soybean oil price from both soybean and soybean oil CIT positions (Table 5, rows 1 and 2). However, when both position variables are included (row 3), it is apparent that the soybeans position variable is dominant and soybean oil positions may be dropped from the test equation. The soybean meal test fails to show statistically significant evidence of a causal link (Table 4, row 4).

These outcomes reinforce the earlier finding that CIT positions changes in the soybean market are causally related to soybean returns. These impacts become even more clearly apparent when we look at the soybean oil market. Soybean oil prices are arbitraged towards soybean prices through the crush spread which reflects processing costs and which will be largely independent of futures market activity. As index-based buying bids up soybean futures prices, soybean oil and meal prices are therefore pulled up in tandem. Possibly as the result of lower liquidity, these impacts are more easily apparent in the soybean oil market than in the soybean market itself.

\section{Granger-causality tests for commodity price indices}

Gilbert (2010b) found that CIT position changes Granger-cause changes in the monthly IMF food price index. ${ }^{7}$ This index includes the prices of crops which are traded on futures markets but also many others for which there are no futures markets (for example sorghum and

\footnotetext{
${ }^{7}$ Source: IMF, International Financial Statistics.
} 
sunflower oil). If the mechanism through which change in CIT positions are related to prices arises directly out of CIT trading itself, we would expect a weak or non-existent relationship between changes in CIT positions on agricultural futures markets and changes in this index.

We test this view using an aggregate index formed from the 12 contracts which the CFTC covers in the Supplementary COT reports. These contracts are only approximately equal in size. Consequently, the index is formed as the weighted sum of the reported positions where the weights are such as to give each weighted contract the same value as one CBOT wheat contract on the initial date in the sample (3 January 2006). The index therefore may be interpreted as the number of equivalent CBOT wheat contracts. Following Gilbert (2010b), we convert the index from a weekly onto a monthly basis by taking the final date of the index in each calendar month. The sample is April 2006 to December 2011.

The test statistic for the hypothesis that changes in the US CIT agricultural futures market positions do not Granger-cause changes in the IMF food price index is given in the top row of Table 6 . The null hypothesis is rejected at the $10 \%$ but not the $5 \%$ level. This weak result is consistent with the results obtained for the futures market returns. In rows 2-5 of the table, the test is repeated for the three remaining components of the IMF's non-fuel commodity price index (beverages, agricultural raw materials and metals and minerals) and for the overall index. The final row of the table repeats the test for the IMF's index of crude oil prices. ${ }^{8}$ Excepting the case of beverages, the tests give clear rejections of Granger noncausality. CIT investment in agricultural markets does Granger-cause non-agricultural commodity returns.

These results give rise to a double paradox. First, the evidence that index positions influence, or are otherwise related to, aggregate commodity price indices is much stronger than the evidence that positions in specific markets influence returns in that market. Second, the relationship between changes in agricultural CIT positions and changes in commodity indices is stronger for the non-agricultural than for the agricultural indices.

It is evident that there cannot be a direct link from trading in agricultural futures to changes in either those agricultural prices which are not traded on a futures exchange or on non-agricultural commodities prices, such as metals and crude oil. This is, therefore, a case in which a finding of Granger-causality cannot plausibly be interpreted as implying structural

\footnotetext{
${ }^{8}$ This is an equally weighted average of the WTI, Brent and Dubai crude oil prices.
} 
causality. The link uncovered by these tests must therefore be informational and not causal. Beliefs or information that are relevant to future changes across the range of commodity prices are reflected in changes in agricultural CIT positions in the weeks and months prior to these price movements.

\section{Do CIT positions impact futures prices?}

We have reported a large number of results which, taken individually, have mixed implications. Considering first the Granger-causality tests on the futures prices, soybean oil is the single clear and unambiguous case in which CIT positions Granger-cause returns. For soybean oil, the null hypothesis of Granger-non-causality is rejected at the $99 \%$ level. For corn, there is weak evidence for Granger-causality but the coefficient sign is problematic.

Looking at the contracts on an individual basis, this appears to provide convincing evidence that CIT activity is a generator of soybean oil returns. However, if we take the six tests as being independent, then, on the null hypothesis of no causal impact and using the binomial distribution, there is a probability of 5.9\% that one or more rejections will take place at the $99 \%$ level. If the soybean results were the only basis for inferring CIT causal impact, it would be possible to regard this single rejection as having arisen from sampling variation - see Sanders and Irwin (2011a). This conclusion represents the current consensus in the academic literature.

Granger-causality tests are restricted to looking at causation from past variables, here variables lagged by one week. Market microstructure theory predicts that any impacts from trading should be impounded in prices very rapidly. If that is the case, Granger-causality tests will have low power, i.e. they may fail to reject the null hypothesis of no impact with high frequency. For this reason, we augmented the Granger-causality tests by contemporaneous tests which look for impacts of CIT activity within the same trading week. Consistently with the contemporaneous correlation of CIT position changes with price returns across the range of agricultural futures prices, these tests provide much stronger evidence for CIT impact. Causal impact is seen in soybeans, soybean oil and $\mathrm{KCBT}$ at the 5\% level. On the null hypothesis of no impact and again supposing independence to allow computation of binomial probabilities, the probability of three rejections out of six at the $95 \%$ level is less than $1 \%$. These results are much more difficult to dismiss as arising solely out of sampling variation. 
On the basis of these two sets of tests, we conclude that there is evidence of a direct causal impact of CIT trading on returns in the soybean complex and also in KCBT wheat. However, there is no evidence for any direct impact in the more liquid CBOT wheat and corn markets. The consensus conclusion that CIT trading has no discernible impact on futures returns, although valid for the important CBOT corn and wheat contracts over the sample period we consider, is exaggerated if applied to the complete range of grains and oilseed markets. It is possible that the relative illiquidity of the soybean complex markets and the KCBT wheat market drives these results. Nevertheless, illiquidity effects are unlikely to be very evident using data at the weekly frequency. This suggests that there may be other explanations of these positive results. We suggest two possible explanations.

The first explanation is suggested by the outcomes of Granger-causality tests on the IMF's commodity price indices. These tests give emphatic support to Granger-causality despite the implausibility of the existence of a direct link from the position changes to the resulting price changes. This is a case in which there is Granger-causality but no structural causality. We suggest that CIT position changes are at least in part driven by information which can predict the general movement in commodity prices over the months that follow. This information might relate to the global macroeconomy. Commodity futures prices, including those of grains and oilseeds, react to this news and CIT investors simultaneously adjust their positions. If this is the case, the macroeconomic news is a missing third variable in the Granger-causality test equations, both those for the changes in the IMF indices and possibly also those for soybean and soybean oil returns.

Mayer (2012) reports evidence of price impact in some periods but not others. The arrival frequency of macroeconomic news varies over time. Information-based theory could account for these differences. This explanation can also account for the stronger impact of CIT-positions in agricultural markets on non-agricultural indices given that the indices are dominated by non-agricultural commodities. Macroeconomic news might predominantly impact energy and metal prices and to a lesser extent agricultural prices. Investors in commodity indices, which are dominated by energy and metals, also react to the new information that impacts energy and metal prices by changing their positions across the commodities in the index. In these circumstances, the link between changes in index positions and agricultural prices would be weaker than those between changes in index positions and non-agricultural markets. 
The second possible explanation for these results is that changes in CIT positions do have a direct impact on crude oil and metals prices in the same way that we have found an impact on soybean, soybean oil and KCBT wheat prices. Because a large proportion of commodity investment tracks one or other of the two major tradable indices, the index we have constructed of CIT positions in US agricultural markets is a reasonable proxy for CIT investment in the crude oil and metals markets. On this explanation, CIT investment is a structural cause of energy and metals returns, and also of returns in the soybeans complex. This second explanation is in line with the findings of Tang and Xiong (2012) who note the comovement of returns of those commodity futures included in tradable commodity indices.

The data we have employed does not permit discrimination between these two possibilities. Our results suggest that the current academic consensus view that CIT has no impact on commodity futures prices is exaggerated - the statistical evidence for such a link is strong, both in the soybeans complex and in energy and metals prices. But interpretation of these results is less clear.

\section{Conclusions}

The results in the literature using Granger-causality analysis are mostly negative. Market microstructure models require that the price impact of trades should be contemporaneous. Granger-causality tests, which rely on the ability of lagged position changes to predict price changes, lack statistical power, especially in liquid markets and when using low frequency data. We therefore also included contemporaneous tests based on IV estimation which exploit the contemporaneous correlation between changes in CIT positions and futures price returns. We also extended the analysis to consider the relationship of changes in CIT positions and changes in the IMF's aggregate commodity price indices.

There is a large literature which claims that CIT activity in agricultural futures markets has no price impact. Sanders and Irwin have contributed extensively to this literature in particular through Sanders and Irwin (2011a). This literature largely relies on Grangercausality tests which fail to take account of positive correlation between CIT position changes and futures returns across the entire range of agricultural futures markets. Market microstructure theory indicates that we should not expect to find Granger-causality in these circumstances even if there is a contemporaneous price impact. These impacts can be analyzed using instrumental variables (IV) methods. 
While our Granger-causality results are in line with the generally negative results reported elsewhere in the literature, the IV results are clearer and are sufficient to demonstrate that there is a causal relationship linking CIT trading to commodity futures returns for a number of important agricultural commodities, in particular the soybean complex. This evidence is too strong to be explained as resulting from sampling variation. There is a tendency for this evidence to be clearest in the less active markets. These results are consistent with the claim that failure of earlier studies to demonstrate such impact may in part have been the result of over-reliance on the Granger-causality methodology.

The most emphatic results we have obtained are those that show that changes in CIT positions in agricultural futures markets help predict price changes across the entire range of commodities which go into the formation of the IMF commodity price indices. These results are clearer for the relationship with non-agricultural than with agricultural prices. This last set of results indicates that the relationship between index investment and changes in commodity prices, in general, may be informational and not causal. The prospectus for index investment is based on portfolio diversification. Within a diversification strategy, sectoral allocations will depend on the expected risk-return profits of the various assets classes. We conjecture that changes in the levels of index investment reflect investors' perceptions of likely future returns on the commodity asset class and that these beliefs are correct to a sufficiently large extent that changes in index investment help predict future commodity price changes. On this view, index investment and commodity price changes therefore share a common driver more than the first being the cause of the second.

This is consistent with the view that at least some index investors are investing in commodity futures as part of an active macroeconomic or financial strategy based on assessments of likely future returns from different asset classes rather than through a passive diversification strategy based on past risk and returns. In this view, these return assessments drive commodity returns and not the index investment activities themselves. Prohibition or limitation of index investment would do nothing to stem these information flows but would reduce liquidity in the markets concerned.

An alternative possibility is that index investment does directly impact energy and metals markets. We lack a long sample of weekly position data for these markets which would permit us to directly examine this hypothesis. However, a proxy position variable 
based on the available weekly position data for the agricultural markets reveals a causal link of some form between index investment and non-agricultural prices.

To summarize, while the evidence that index trading directly impacts agricultural futures prices is confined to a small number of the grains and oilseed markets we have considered, there is nevertheless clear evidence that index trading has played an important information transmission role in both agricultural and non-agricultural markets. In important non-agricultural markets, index trading Granger-causes returns without necessarily being a structural cause. The policy implication is that general restrictions on index-based trading would reduce the efficiency of futures markets but would not have prevented the large price movements seen over recent years.

The prices of food commodities are, of course, particular sensitive from a political standpoint and food price spikes, however caused, impact most acutely on the poor. This makes financial innovation risky when it relates to agricultural markets. It suggests consideration of policies that break the link between food and non-food commodities to limit possible spill-over effects from the latter. A simple way to do this, which falls short of outright prohibition of index trading in agricultural futures, would be to require index providers to unbundle agricultural and non-agricultural offerings and, at the same time, for the index reporting companies (Dow Jones and Standard and Poors) to separate out agriculture from their published commodity indices. 
Figure 1. Commodity index trader (CIT) positions share of total long positions

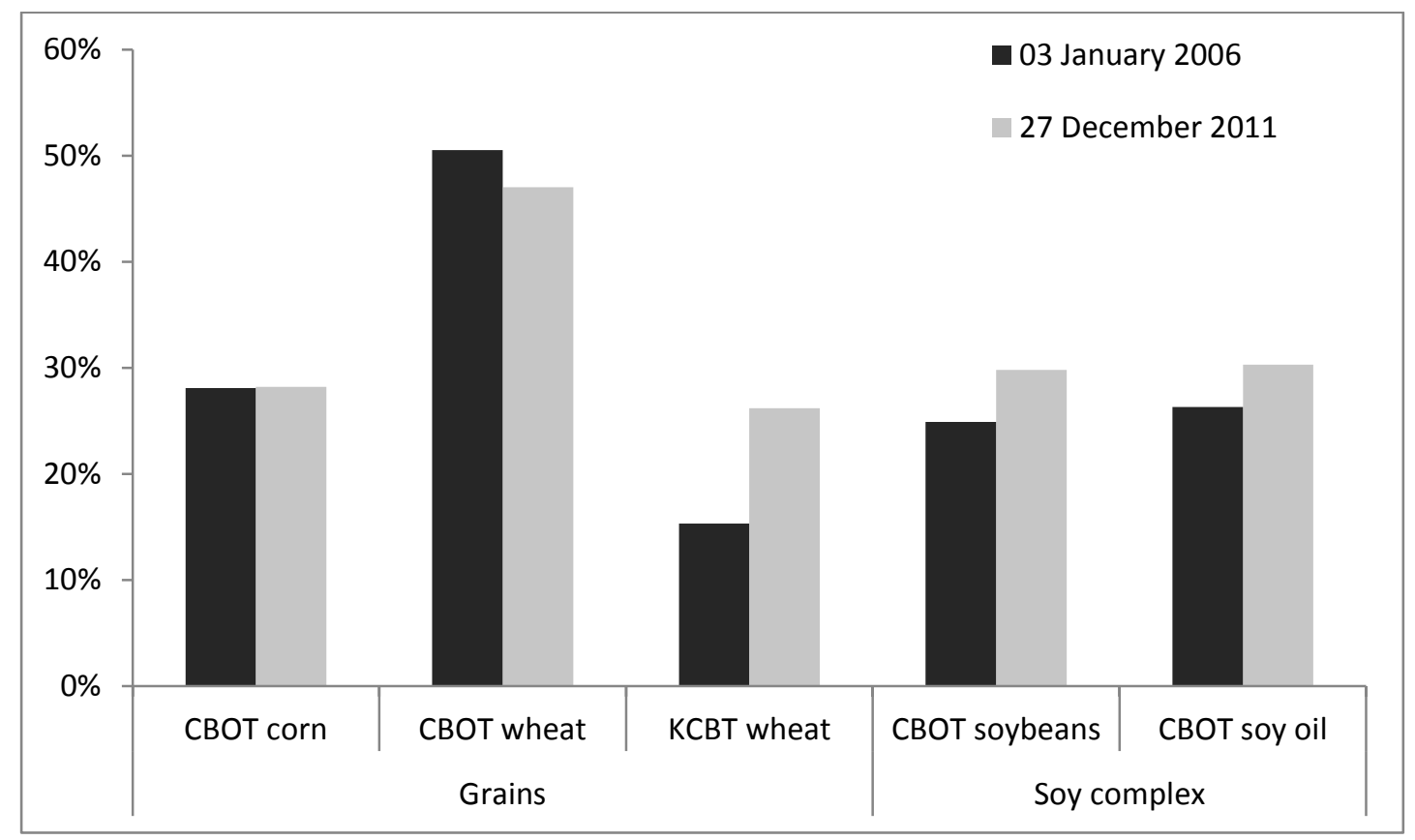

Source: CFTC, Commitments of Traders Reports 
Table 1. Contemporaneous correlations between price returns and index positions, 3 January 2006 to 27 December 2011

\begin{tabular}{lccc} 
& $\begin{array}{c}\text { Correlation } \\
\text { coefficient }\end{array}$ & $t$-statistic & p-value \\
\hline CBOT corn & $0.145^{* *}$ & 2.58 & 0.0103 \\
CBOT soybeans & $0.368 * * *$ & 6.97 & 0.0000 \\
CBOT soybean oil & $0.170 * * *$ & 3.04 & 0.0026 \\
CBOT wheat & $0.179 * * *$ & 3.20 & 0.0015 \\
KCBT wheat & $0.201 * * *$ & 3.60 & 0.0004 \\
\hline
\end{tabular}

Notes: The table reports the correlation coefficient, the $t$ statistics and the p-value testing zero correlation between price returns and contemporaneous index position changes. Rejection at the $1 \%$ level are denote by $* * *$ and those at the $5 \%$ level by $* *$. CBOT stands for Chicago Board of Trade, KCBT for Kansas City Board of Trade. 
Table 2: Granger-causality analysis grains and soybeans, 17 January 2006 to 27 December 2011

\begin{tabular}{lccc}
\hline & $\begin{array}{l}\text { Estimated } \beta \\
\text { coefficient }\end{array}$ & $t$-statistic $\left|t_{\beta}\right|$ & p-value \\
\hline CBOT corn & $-0.61^{*}$ & 1.96 & 0.05 \\
CBOT soybeans & 0.96 & 1.30 & 0.20 \\
CBOT wheat & -0.97 & 1.17 & 0.24 \\
KCBT wheat & 0.94 & 0.40 & 0.69 \\
\hline
\end{tabular}

Notes: The table reports the estimated $\beta$ coefficient, the t-statistic $\left|t_{\beta}\right|$ for the Granger-noncausality tests that index returns do not Granger-cause price returns based on robust standard errors and p-values using equation (3). Rejections at the $10 \%$ level are denoted by *. 
Table 3. Granger-causality test results (CIT positions) for the CBOT soybean oil and soybean meal contracts, 31 January 2006 to 27 December 2011

\begin{tabular}{ccccc}
\hline & Lags & Soybeans & Soybean oil & Joint \\
\hline \multirow{2}{*}{ Soybean oil } & \multirow{2}{*}{3} & $F_{3,299}=3.17^{* *}$ & $F_{3,299}=3.32^{* *}$ & $F_{6,299}=2.85^{* *}$ \\
& & {$[0.025]$} & {$[0.020]$} & {$[0.010]$}
\end{tabular}

Soybean

meal

$\begin{array}{ccc}t_{305}=0.80 & t_{305}=1.03 & F_{2,305}=1.40 \\ {[0.372]} & {[0.312]} & {[0.248]}\end{array}$

Notes: The table reports the $\mathrm{t}$-statistic $\left|\mathrm{t}_{\beta}\right|$ for the Granger-non-causality tests that index returns do not Granger-cause price returns based on robust standard errors and p-values in square brackets for individual lags using either equation (1) or (3), depending on the lag length. Robust F-statistics are reported for the Granger-causality tests that index returns do not Granger-cause price returns with p-values in square brackets. Rejections at the 5\% level are denoted by **. 
Table 4. Contemporaneous test results (CIT positions), 17 January 2006 to 27

December 2011

\begin{tabular}{lccccc}
\hline & Coefficient & $t$-statistic & p-value & Sargan $\chi_{8}^{2}$ & p-value \\
\hline $\begin{array}{l}\text { CBOT } \\
\text { corn }\end{array}$ & -1.014 & -0.97 & 0.332 & 9.88 & 0.274 \\
$\begin{array}{l}\text { CBOT } \\
\text { soybeans }\end{array}$ & $4.758 * *$ & 2.14 & 0.034 & 6.41 & 0.602 \\
$\begin{array}{l}\text { CBOT } \\
\text { wheat }\end{array}$ & -1.245 & -0.47 & 0.637 & 13.39 & 0.084 \\
$\begin{array}{l}\text { KCBT } \\
\text { wheat }\end{array}$ & $24.92 * *$ & 2.47 & 0.014 & & \\
& & & & & \\
\end{tabular}

Notes: Instruments: Lagged returns and lagged CIT position changes for all four grains, lagged change in the log DJ-UBS commodity price index, lagged VIX. 
Table 5. Contemporaneous test results (CIT positions), soybean oil and soybean meal, 17 January 2006 to 27 December 2011

\begin{tabular}{ccccc}
\hline & Soybeans & Soybean oil & Joint test & Sargan \\
\hline & \multicolumn{3}{c}{$6.59 * *$} \\
& $\left(t_{308}=2.00\right)$ & & $\chi_{10}^{2}=12.66$ \\
& & {$[0.046]$} & & {$[0.243]$} \\
Soybean oil & $7.01 * * *$ & $\left(t_{308}=3.08\right)$ & & $\chi_{10}^{2}=8.36$ \\
& {$[0.002]$} & & & {$[0.594]$} \\
& $6.74 * *$ & 0.59 & $F_{2,307}=$ & $\chi_{9}^{2}=8.41$ \\
& $\left(t_{307}=2.28\right)$ & $\left(t_{307}=0.14\right)$ & $4.76^{* * *}$ & {$[0.494]$} \\
& {$[0.023]$} & {$[0.887]$} & {$[0.009]$} & \\
\hline & 3.42 & & & $\chi_{9}^{2}=7.84$ \\
Soybean meal & $\left(t_{308}=1.48\right)$ & & & {$[0.551]$} \\
\hline
\end{tabular}

Notes: The table reports the estimated $\beta$ coefficient, $t$ - and F-statistics and p-values in square brackets. Rejections at the $10 \%$ level are denoted by *, at the $5 \%$ level are denoted by $* *$ and those at the $1 \%$ level by $* * *$. Instruments: Soybean meal, as in Table 3. Soybean oil, as in Table 4 plus lagged soybean oil return and lagged soybean oil position change. 


\begin{tabular}{lllll}
\hline \multicolumn{5}{c}{ Table 6: Granger-causality analysis for IMF indices, April 2006 to December 2011} \\
\hline Food & Lags & Test & Statistic & p-value \\
Beverages & 1 & $\mathrm{t}_{66}$ & $1.80^{*}$ & 0.076 \\
Agricultural raw materials & 2 & $\mathrm{~F}_{2,64}$ & 1.49 & 0.234 \\
Metals and minerals & 2 & $\mathrm{~F}_{2,64}$ & $6.12^{* * *}$ & 0.004 \\
Non-energy index & 1 & $\mathrm{~F}_{2,64}$ & $6.15^{* * *}$ & 0.001 \\
Crude oil & 1 & $\mathrm{t}_{66}$ & $2.63^{* *}$ & 0.011 \\
\hline
\end{tabular}

Notes: The table reports the $\mathrm{t}$ or $\mathrm{F}$ statistics for the Granger-non-causality tests that index returns do not Granger-cause returns in the relevant indices based on robust standard errors and p-values using equation (3). Lag lengths were selected using the AIC. Rejections at the $10 \%, 5 \%$ and $1 \%$ levels are denoted by ${ }^{* * *}$ and ${ }^{* * *}$ respectively. 


\section{REFERENCES}

Acharya, V.V., Lochstoer, L.A. and Ramadorai, T. 'Limits to arbitrage and hedging: Evidence from commodity markets', NBER Working Paper 16875 (Cambridge MA: NBER, 2011).

Amihud, Y. and Mendelson, H. 'Asset pricing and the bid-ask spread', Journal of Financial Economics, Vol. 17, (1986) pp. 223-249.

Aulerich, N.M., Irwin, S.H. and Garcia, P. 'Bubbles, food prices, and speculation: Evidence from the CFTC's daily Large Trader Data files', Paper prepared for presentation at the NBER Conference on "Economics and Food Price Volatility" in Seattle, August 15-16, 2012 (Seattle, 2012).

Brunetti, C. and Büyüksahin, B. 'Is speculation destabilizing?' Working Paper (Washington D.C.: Commodity Futures Trading Commission, 2009).

Bryant, H.L., Bessler, D.A. and Haigh, M.S. 'Causality in futures markets', Journal of Futures Markets, Vol. 26, (2006) pp. 1039-1057.

Capelle-Blancard, G. and Coulibaly, D. 'Index trading and agricultural commodity prices: A panel Granger causality analysis', Working Paper No. 2011-28 (Paris: Centre D'Etudes Prospectives Et D'Informations Internationales, 2011).

Commodity Futures Trading Commission (CFTC) 'Commission Actions in Response to the "Comprehensive Review of the Commitments of Traders Reporting Program", (Washington D.C.: Commodity Futures Trading Commission, December 2006).

de Jong, F. and Rindi, B. The Microstructure of Financial Markets (Cambridge: Cambridge University Press, 2009).

Fattouh, B., Kilian, L. and Mahadeva L. 'The role of speculation in oil markets: What have we learned so far?' Energy Journal, Vol. 34, (2013) pp. 7-33.

Gilbert, C.L. 'Commodity speculation and commodity investment', in G. Rapsomanikis and A. Sarris (eds.) Commodity Market Review 2009-10 (Rome: FAO, 2010a, pp. 25-46).

Gilbert, C.L. 'How to understand high food prices', Journal of Agricultural Economics, Vol. 61, (2010b) pp. 398-425.

Gorton, G. and Rouwenhorst, K.G. 'Facts and fantasies about commodity futures', Financial Analysts Journal, Vol. 62, (2006) pp. 47-68.

Grossman, S. and Stiglitz, J.E. 'On the impossibility of informationally efficient markets', American Economic Review, Vol. 70, (1980) pp. 393-408.

Hamilton, J.D. and Wu, J.C. 'Effects of index-fund investing on commodity futures prices', Chicago Booth Research Paper (Chicago: Chicago Booth School of Business, 2013).

Hernandez, M. A. and Torero, M. 'Examining the dynamic relation between spot and futures prices of agricultural commodities', in G. Rapsomanikis and A. Sarris (eds.) Commodity Market Review 2009-10 (Rome: FAO, 2010, pp. 47-86).

Holthausen, R.E., Leftwich, R. and Mayers, D. 'The effects of large block transactions on security prices: a cross-sectional analysis', Journal of Financial Economics, Vol. 19, (1987) pp. 237-267.

Hoover, K.D. Causality in Macroeconomics (Cambridge: Cambridge University Press, 2001).

Irwin, S.H. "Commodity index investment and food prices: Does the "Masters Hypothesis" explain recent price spikes?, Agricultural Economics, Vol. 44, (2013).

Irwin, S.H. and Sanders, D.R. 'Index funds, financialization, and commodity futures markets', Applied Economic Perspectives and Policy, Vol. 33, (2011) pp. 1-31.

Irwin, S.H. and Sanders, D.R. 'Testing the Masters Hypothesis in commodity futures markets', Energy Economics, Vol. 34, (2012a) pp. 256-269. 
Irwin, S.H. and Sanders, D.R. 'Financialization and structural change in commodity futures markets', Journal of Agricultural and Applied Economics, Vol. 44, (2012b) pp. 371-396.

Kyle, A. 'Continuous auctions and insider trading', Econometrica, Vol. 53, (1985) pp. 13151335.

Markowitz, H.M. 'Portfolio selection', Journal of Finance, Vol. 7 (1952) pp. 77-91.

Masters, M.W. 'Testimony before the U.S. Senate Committee of Homeland Security and Government Affairs' (Washington D.C., 20 May 2008).

Mayer, J. 'Financialized commodity markets: the role of information and policy issues', Économie Appliquée, Vol. 44, (2011) 5-34.

Mayer, J. 'The growing financialisation of commodity markets: divergences between index investors and money managers', Journal of Development Studies, Vol. 48, (2012) pp. 751767.

Newbold, P. 'Causality Testing in Economics', in O.D. Anderson (ed.) Time Series Analysis: Theory and Practice I, (Amsterdam: North Holland Publishing Company, 1982, pp. 701716).

O’Hara, M. Market Microstructure Theory (Oxford: Blackwell, 1995).

Rouwenhorst, K.G. and Tang, K. 'Commodity investing', Annual Review of Financial Economics, Vol. 4, (2012) pp. 447-467.

Sanders, D. R. and Irwin, S.H. 'New Evidence on the impact of index funds in U.S. grain futures markets', Canadian Journal of Agricultural Economics, Vol. 59, (2011a) pp. 519532.

Sanders, D. R. and Irwin, S.H. 'The impact of index funds in commodity futures markets: A systems approach', Journal of Alternative Investments, Vol. 14, (2011b) pp. 40-49.

Sanders, D. R. and Irwin, S.H. 'Measuring index investment in commodity futures markets', Energy Journal, Vol. 34, (2013) pp. 105-127.

Sanders, D. R., Irwin, S.H. and Merrin, R.P. 'Smart money: The forecasting ability of CFTC large traders in agricultural futures markets', Journal of Agricultural and Resource Economics, Vol. 34, (2009) pp. 276-296.

Sanders, D. R., Irwin, S.H. and Merrin, R.P. 'The adequacy of speculation in agricultural futures markets: Too much of a good thing?', Applied Economic Perspectives and Policy, Vol. 32, (2010) pp. 77-94.

Sargan, J.D. 'The estimation of economic relationships using instrumental variables', Econometrica, Vol. 26, (1958) pp. 393-415.

Scherer, V. and He, L. 'The diversification benefits of commodity futures indexes: a meanvariance spanning test', in F.J. Fabozzi, R. Füss and D.G. Kaiser (eds.) The Handbook of Commodity Investing (Hoboken,NJ: Wiley, 2008, pp. 241-65).

Scholes, M. 'The market for securities: substitution versus price pressure and the effects of information on share prices', Journal of Business, Vol. 45, (1972) pp. 179-211.

Shleifer, A. 'Do demand curves for stocks slope down?', Journal of Finance, Vol. 41, (1986) 579-590.

Sockin, M. and Xiong, W. 'Feedback effects of commodity futures prices', NBER Working Paper 18906 (Cambridge MA: NBER, 2013).

Stoll, H.R. 'Friction', Journal of Finance, Vol. 55, (2000) pp. 1479-1514.

Stoll, H.R. and Whaley, R.E. 'Commodity index investing and commodity futures prices', Journal of Applied Finance, Vol. 20, (2010) pp. 7-46.

Tang, K. and Xiong, W. 'Index investment and the financialization of commodities', Financial Analysts Journal, Vol. 68, (2012) pp. 54-74.

UNCTAD Trade and Development Report 2011: Post-crisis policy challenges in the world economy (New York and Geneva: United Nations, 2011). 